\title{
Da servidão irrestrita à simpatia cooperante: reflexões a partir de Georg Herbert Mead e Monteiro Lobato ${ }^{1}$
}

\section{From unfettered servitude to cooperative sympathy: reflections drawing on Georg Herbert Mead and Monteiro Lobato}

\author{
Cláudio Almir Dalbosco (i) 2 \\ Claudeonor Antônio de Vargas (ii) 3 \\ Renata Maraschin (iii)
}

\begin{abstract}
(i) Universidade de Passo Fundo - UPF, Passo Fundo, RS, Brasil. https:/ / orcid.org/0000-0003-34082975, vcdalbosco@hotmail.com.

(ii) Universidade de Passo Fundo - UPF, Passo Fundo, RS, Brasil. https:/ /orcid.org/0000-0003-22520026, vargasclaudeonorvargas@gmail.com.

(iii) Universidade de Passo Fundo - UPF, Passo Fundo, RS, Brasil. https://orcid.org/0000-0003-05951641, rechinpf@gmail.com.
\end{abstract}

\begin{abstract}
Resumo:
O ensaio aborda o problema da formação social do self. Dividindo-se em quatro passos, reconstrói, no primeiro, aspectos da teoria interacionista da educação de Mead, enfatizando sua dimensão social-intersubjetiva. No segundo passo recorre ao conto "Negrinha", de Monteiro Lobato, para mostrar, à contrapelo, como a ação humana pode descambar facilmente para a obediência irrestrita e o quanto isso marca destrutivamente as formas de vida. Confronta, no terceiro passo, o conto de Monteiro Lobato por meio de aspectos da teoria da ação de Mead, evidenciando a tensão constitutiva da formação humana como autoformação. Por fim, reconstrói, no quarto passo, um traço da formação como autoformação, herdado por Mead da Modernidade, que o auxilia a colocar a simpatia cooperante como núcleo ético da formação do si-mesmo. O ensaio conclui afirmando que perspectivas intersubjetivas são mais apropriadas, em contextos sociais plurais, para livrar o ser humano de suas diferentes formas de servidão.

Palavras-chave: self, educação, autoformação, liberdade, servidão
\end{abstract}

\footnotetext{
${ }^{1}$ Normalização, preparação e revisão textual: Lucas Giron (Tikinet) - revisao@tikinet.com.br

${ }^{2}$ Bolsista de produtividade CNPq.

${ }^{3}$ Bolsista Prosuc Capes
} 


\title{
pro.posıções
}

$e$-ISSN 1980-6248

http://dx.doi.org/10.1590/1980-6248-2019-0075

\begin{abstract}
:
The essay seeks to address the problem of the social formation of the self. Divided in four parts, in the first one, it reconstructs aspects of Mead's interactionist theory of education, emphasizing its social, intersubjective dimension. In the second part, it recounts the short story "Negrinha", by Monteiro Lobato, to show, against the grain, how buman action can easily fall into unrestricted obedience and how it destructively marks the ways of life. In the third part, the essay confronts Monteiro Lobato's short story with aspects of Mead's theory of action, evidencing the constitutive tension of human formation as self-formation. Finally, it reconstructs a trait of formation as selfformation, inherited from Modernity by Mead, helping it place cooperative sympathy as the ethical core of self-formation. The essay concludes that intersubjective perspectives are more appropriate, in plural social contexts, to rid bumans of different forms of servitude.
\end{abstract}

Keywords: self, education, selfformation, freedom, servitude

\section{Introdução}

A formação de um ser humano capaz de pensar por si mesmo, deliberando livremente sobre suas escolhas e assumindo de maneira responsável as consequências de sua ação, sempre foi uma preocupação central das teorias educacionais, desde a antiguidade até nossos dias. De acordo com esta longa tradição, o status da condição humana é indispensável para pensar a felicidade humana, alicerçada no convívio social solidário e cooperativo, pois quem não é capaz de pensar e agir por si mesmo não possui as condições iniciais mínimas para deliberar ética e participativamente no espaço público que une os seres humanos ${ }^{4}$.

Na Modernidade, o vínculo entre autonomia individual e participação ético-política no espaço público amplia-se enormemente, visando alcançar a humanidade como um todo. Com Jean-Jacques Rousseau (1999) e Immanuel Kant (1998), por exemplo, a teoria educacional assume posição contrária a qualquer forma de servidão humana, tornando o autogoverno individual condição indispensável de formas de vida modernamente republicanas e democráticas. Em Rousseau, a crítica às diferentes formas de obediência irrestrita mostra-se

\footnotetext{
${ }^{4}$ É importante notar que esta ampla temática constitutiva da tradição pedagógica ocidental ecoa diretamente na pedagogia brasileira contemporânea, influenciando decisivamente pedagogos como Anísio Teixeira (2000) e Paulo Freire (2009).
} 


\section{pro.posıções}

$e$-ISSN 1980-6248

exemplarmente na defesa da autonomia infantil, sintetizada pelo seu credo pedagógico de tomar a criança como criança, contra a postura educacional estandarte da época, a qual a considerava adulto em miniatura. Segundo tal teoria educacional, do autogoverno infantil, baseado no princípio da liberdade bem regrada, dependem as amplas estruturas institucionais que dinamizam espaços sociais mais amplos e abertos, nos quais as capacidades humanas podem se desenvolver livremente. Em Kant, uma das vertentes de sua crítica contra qualquer forma de servidão humana manifesta-se na tensão entre menoridade e maioridade. O filósofo de Königsberg considera - e este é o aspecto de sua crítica que precisamente nos interessa - o ser humano como parte responsável pela sua própria menoridade, pois, por preguiça e covardia, ele não ousa pensar por si mesmo, tornando-se, assim, de certo modo, autoculpável (Selbstschuld) por sua própria servidão. Com isso, Kant toma a disposição individual como aspecto nuclear da formação humana: não há formação possível do ser humano sem que ele próprio esteja decidido a se formar. Contudo, acentua, assim como Rousseau já havia feito antes, que o desenvolvimento das disposições individuais, ou seja, das capacidades humanas, depende de seu entrelaçamento com estruturas sociais e institucionais. ${ }^{5}$

Deste modo, tanto em Rousseau como em Kant, formação tem a ver com autoformação. Ou seja, não há formação sem um nível de autorreflexividade crítica, na qual o sujeito desenvolve a capacidade de pensar por conta própria, sobre si mesmo e sobre o mundo que o cerca. Contudo, o âmbito da formação do si-mesmo (soi-même/Selbst) fica ainda muito limitado, nestes autores, à esfera individual, embora ambos não deixem de inserir a ação humana no âmbito social mais amplo. De qualquer forma, Rousseau e Kant assinalam, cada um à sua maneira, a tensão entre indivíduo e sociedade como constitutiva da formação humana e preocupam-se com as diferentes formas de corrupção geradas pelo entrelaçamento entre condição humana e vida social. Se a formação do si-mesmo passa a ser, na Modernidade, garantia indispensável às formas de vida democráticas, a apreensão da tensão que a constitui será compreendida de maneira mais adequada somente nas primeiras décadas do século XX, com o esforço teórico empreendido por Georg Herbert Mead (1992). Com sua teoria da individuação social, Mead mostra que a formação do si-mesmo (self) depende do social na mesma medida em que a socialização humana mais ampla lança suas próprias raízes na formação vagarosa, contínua e cheia de percalços de cada self individualizado. Para pensar de maneira

\footnotetext{
${ }^{5}$ Para uma interpretação do pensamento pedagógico de Rousseau e Kant na perspectiva da formação humana, ver Claudio A. Dalbosco (2016, 2011).
} 


\section{pro.posições}

$e$-ISSN 1980-6248

mais apropriada a tensão entre o individual e o social, Mead desenvolve - nisso consiste sua originalidade - a teoria da bifurcação do self em $I$ e me, constituída pela interação social mediada linguisticamente ${ }^{6}$.

No presente ensaio pretendemos refletir sobre a formação do self em Mead, compreendendo-a como forma de aprofundamento e, por isso, em certo sentido, de atualização da moderna problemática de formação do sujeito autônomo. Dividimos o ensaio em quatro tópicos: no primeiro reconstruímos a gênese social do self; no segundo, oferecemos uma síntese interpretativa do conto "Negrinha", de Monteiro Lobato, tomando-o como exemplo paradigmático do self deformado; no terceiro confrontamos aspectos da formação do self em Mead com o referido conto de Lobato, visando elucidar a tensão que cruza a formação do simesmo, a saber, entre sua busca permanente por ser ele mesmo (si próprio) e os riscos inerentes a tal busca; por fim, no quarto tópico, considerando os resultados obtidos nos tópicos anteriores, refletimos sobre a ideia de educação como formação bumana.

\section{A gênese social do self}

Georg Herbert Mead tornou-se importante no âmbito da filosofia social contemporânea por ter pensado de maneira original a tensão entre indivíduo e sociedade e, especialmente, o problema da formação social do self. Professor da Universidade de Chicago (Estados Unidos) e amigo de John Dewey, foi autor de vasta produção intelectual ${ }^{7}$. Seu principal trabalho, Mind, self and society (Espirito, si-mesmo e sociedade), foi organizado e publicado posteriormente, após sua morte, pelo seu aluno e discípulo Charles W. Morris. Formado na tradição do idealismo alemão e profundo conhecedor da filosofia de Georg F. Hegel, formulou suas ideias dialogando com o que havia de mais avançado na época, em termos de psicologia social, expressada no pensamento de John B. Watson e Wilhelm Wundt, os quais, por sua vez, eram profundamente tributários da biologia evolucionista de Charles Darwin.

\footnotetext{
${ }^{6}$ Vários autores contemporâneos, entre eles Jürgen Habermas (1992, pp. 187-241) e Axel Honneth (1994, pp. 114147), destacam a importância do giro linguístico efetuado por Georg Herbert Mead e, com isso, seu papel crítico à filosofia da consciência. Para uma interpretação de Mead como crítico da filosofia da consciência (paradigma da subjetividade), ver Claudio A. Dalbosco (2010, pp. 213-243).

7 Devemos a Hans Joas (2000) uma das melhores biografias intelectuais sobre Georg Herbert Mead. Além de localizar o pensamento de Mead no cenário intelectual e político americano, Joas resgata suas heranças europeias, principalmente vinculadas ao idealismo alemão.
} 


\section{pro.posıções}

$e$-ISSN 1980-6248

Para dar conta da exposição resumida da formação social do self-nosso propósito neste tópico - investigamos brevemente o papel atribuído por Mead à linguagem como condutora principal da interação social mediada simbolicamente; além disso, tratamos da estrutura bifurcada do self em I e me; e, por fim, refletimos sobre o papel da simpatia como amálgama ético-afetivo indispensável à socialização cooperativa do si-mesmo.

A emergência do self, segundo Mead, só é possível no processo social levado a termo por intermédio da interação mediada linguisticamente, a qual contém a capacidade de gerar provocações recíprocas (estímulos recíprocos, na linguagem semi-behaveorista de Mead) entre os interlocutores. Por conta deste caráter simbólico, oriundo do emprego de signos dotados de significados construídos na interação humana, a comunicação assume centralidade. Segundo Mead, "A importância crítica da linguagem no desenvolvimento da experiência humana reside no fato de que o estímulo pode reagir sobre o indivíduo que fala do mesmo modo que reage sobre outro"8 (Mead, 1992, p. 69). O conteúdo desta passagem ressalta o aspecto vinculante inerente à linguagem humana, gerado pela compreensão mútua do significado daquilo que é expressado por meio do gesto vocal. Contudo, para que a linguagem possa alcançar este nível de reciprocidade que assegura o processo de internalização e externalização constante e consciente, é preciso que ocorra a passagem do gesto para o símbolo. Segundo Mead, "A comunicação consciente ... surge quando os gestos se convertem em símbolos [grifo nosso], quer dizer, quando chegam a ter, para os indivíduos que os fazem e para os que reagem a eles, significações definidas, em termos do comportamento subsequente das pessoas que o executam"9 (Mead, 1992, p. 69). Enquanto o gesto caracteriza a conduta instintiva, na qual o indivíduo reage movido por impulsos sem ter as condições de internalizar as reações dos outros e suas próprias reações, o símbolo é eivado de significação na medida em que assegura o processo criativo de reação desencadeada contra outras reações. Ou seja, o símbolo possui um nível de significação que simplesmente está ausente no gesto. Nas palavras de Mead: “Quando falamos da significação do que fazemos, estamos convertendo em um estímulo para a ação a reação que estamos a ponto de executar"10 (Mead, 1992, p. 72).

\footnotetext{
8 "The critical importance of language in the development of human experience lies in this fact that the stimulus is one that can react upon the speaking individual as is reacts upon the other".

9 "Conscious communication ... arises when gesture become signs, that is, when they come to carry for the individuals making them and the individuals responding to them, definite meanings or significations in terms of the subsequent behavior of the individuals making them".

10 "When we speak of the meaning of what we are doing we are making the response itself that we are on the point of carrying out a stimulus to our action".
} 


\section{pro.posıções}

$e$-ISSN 1980-6248

Dito de outra maneira, a significação ganha evidência na ação e reação do indivíduo ao que está sendo simbolicamente comunicado e na repercussão do expressado por meio do gesto vocal que organiza a conduta dos indivíduos no percurso atual e na sequência do ato social. Isto porque o gesto vocal, agora em nível de símbolo significante, produz igual estímulo no indivíduo que o emite e naquele que o recebe. Este processo básico da significação efetiva-se, então, na tríplice relação entre (i) o ato gestual de um indivíduo que provoca (ii) uma reação de adaptação em outro indivíduo e (iii) na finalização de um dado ato social iniciado pelo primeiro indivíduo. Ainda, em evidente crítica às concepções filosóficas da consciência, Mead, ao situar a significação no processo da experiência em curso, distingue-a da pretensão de adição psíquica ao ato, separando-a do conceito tradicional de consciências, desvinculada da concretude da interação humana ${ }^{11}$.

A transformação do gesto primitivo em gesto vocal - o qual, por sua vez, se constitui em símbolo significante com a capacidade de imbricar ação e reação mútuas, ao ordenar a conduta dos indivíduos - está na base da organização social. Emerge, assim, uma concepção de sociedade que carrega em si a possibilidade da interlocução entre as diversas visões de mundo, unificando-as sem que isto signifique a extinção desta diversidade. Ao contrário, o fato de a sociedade se constituir de relações marcadas pela singularidade dos diferentes si-mesmos e interesses sociais geralmente conflitantes, é o que assegura a condição para que aconteça a convivência humana com respeito às diferenças. É este traço marcante da relação entre diferentes si-mesmos que possibilita a emergência do self na relação tensional entre o $I$ e o me e institui uma fase vital à organização da ação humana. Segundo Mead: “A reflexão ou a conduta reflexiva surge somente sob as condições da consciência de si, tornando possível o controle e a organização intencional, por parte do organismo individual, de sua conduta, com referência ao meio social e físico ..."12 (Mead, 1992, p. 91).

Deste modo, o símbolo significante possibilita que a ação humana alcance um nível de reflexividade inexistente no âmbito do ato gestual. Tal reflexividade, que é dada socialmente e de maneira interativa, propicia a consciência de si, a qual é o nível mais elevado alcançado por um

\footnotetext{
11 Neste sentido, ao se opor aos modelos da filosofia da consciência, Mead constitui-se em um dos fundadores contemporâneos da filosofia da intersubjetividade. Sob este aspecto, ver a leitura de Jürgen Habermas (1992, pp. 187-241) e Ernst Tugendhat (1979, pp. 245-292). Ver também Claudio Almir Dalbosco (2014).

12 "Reflection or reflective behavior arises only under the conditions of self-consciousness, and makes possible the purposive control and organization by the individual organism of its conduct, with reference to its social and physical environment ...".
} 


\section{pro.posıções}

$e$-ISSN 1980-6248

organismo vivo. Consciência e consciência de si são dois conceitos caros à tradição filosófica moderna, especialmente hegeliana, profundamente transformados por Mead, ao interpretá-los pela ótica da linguagem, ou seja, pela perspectiva da ação humana mediada simbolicamente. Consciência não é mais uma entidade mental abstrata, uma substância que reside em algum lugar na cabeça do ser humano e que, impulsionada por forças externas, no caso, por ideias, move o ser humano para o pensamento. Ao contrário, na perspectiva de Mead, consciência é um agir reflexivo que surge e se desenvolve no âmbito concreto da experiência humana, ganhando sentido por meio da capacidade significante do símbolo. Consciência de si, por sua vez, é o nível mais elevado da ação humana na medida em que, por meio do aspecto vinculante do símbolo, ela torna o ser humano aberto a novas experiências, possibilitando-lhe reelaborar permanentemente suas próprias ações. Do ponto de vista da interação social mediada linguisticamente, a consciência de si significa a capacidade humana de adotar a atitude dos outros e atuar sobre si mesmo de maneira semelhante como atuam os outros (Mead, 1992, p. 171).

Em síntese, a teoria da linguagem de Mead baseia-se na distinção entre gesto e símbolo. O gesto é um tipo de reação que o agente provoca nos outros sem se deixar afetar pela própria reação, caracterizando, metaforicamente, um caminho de mão única, uma vez que afeta sem ser afetado. Ele indica, por isso, um estado de passividade ou indiferença que bloqueia ou impede a relação social. Neste sentido, o ato gestual não pode dar origem à relação social porque não é capaz de significação internalizada. De outra parte, Mead concebe o símbolo significante como aprofundamento extraordinário do ato gestual e, em certo sentido, como sua própria superação. Deste modo, o símbolo ocorre quando a ação produz o mesmo efeito sobre o próprio indivíduo que a realiza e não só no indivíduo ao qual se destina. O símbolo significante possui, portanto, a capacidade extraordinária de provocar reciprocidade, possibilitando a internalização reflexiva da própria ação humana. Por isso, é uma via de mão dupla, que não só vai para frente, numa única direção, mas, retornando pela outra pista, proporciona internalização da reação que a ação provocou nos outros.

Esta capacidade autorreflexiva do símbolo possibilita a bifurcação do self e, nesta estrutura bifurcada, o próprio encontro consigo mesmo. Não é fácil compreender o que Mead entende por $I$ e me e como ele coloca este duplo movimento constitutivo da ação humana na base da formação do si-mesmo. De qualquer sorte, é pela tensão entre I e me que o selfrepresenta o nível mais evoluído da sociedade, adquirindo a consciência de si, que lhe possibilita tornar-se sujeito de seu próprio processo de formação. Do ponto de vista da linguagem condutista 


\section{pro.posições}

http://dx.doi.org/10.1590/1980-6248-2019-0075

$e$-ISSN 1980-6248

adotada por Mead, o I é a reação do organismo às atitudes dos outros; é, mais propriamente, a ação do indivíduo ante a situação social que existe dentro de sua própria conduta, podendo incorporá-la somente depois de ter levado a cabo sua ação. Não representa de modo algum a simples assimilação do que chega até ele do ambiente externo, especificamente das pressões sociais. Por isso, o I preserva - e isto é decisivo para a formação autônoma do si-mesmo - a possibilidade tanto da liberdade como da iniciativa própria. A liberdade criadora inerente ao $I$ impede que as ações do self sejam inteiramente calculadas e completamente dominadas pela ação ambiental externa. Ora, este nível de imprevisibilidade que marca a ação do $I$ torna-se decisivo para que o self possa, ao menos como possibilidade, resistir a uma assimilação completa com o ambiente externo. O me representa, por sua vez, a organização definida da sociedade e o modo como ela chega até o self, provocando sua reação. Sendo assim, o me assume nitidamente uma dimensão social na medida em que representa a atitude dos outros que chagam até o self. Por trazer a situação social para dentro do ser humano, o me torna-se uma espécie de condutor social, sem o qual o próprio ser humano permaneceria um ente fechado em si mesmo.

Em síntese, enquanto o I representa o modo próprio como o ser humano elabora o que é comum a todos, o me significa o que é comum a todos; enquanto o I significa a internalização e dramatização que o ser humano faz do que chega até ele da sociedade, o me é o que faz a voz da sociedade chegar até o ser humano. Mostra-se com isso o duplo processo que constitui a gênese social do self: a existência da voz da sociedade e sua respectiva dramatização pelo próprio indivíduo. Deste modo, embora $I$ e me não sejam a mesma coisa, um não existe sem o outro e somente atuando juntos formam o self. Temos assim, segundo Mead, uma maneira de compreender como se forma a experiência social e o self no âmbito de tal experiência. Ora, se o self não se forma sem as pressões do ambiente, é por sua liberdade criadora, representada pelo $I$, que ele (o self) pode elaborar reflexivamente o que vem do ambiente, o que mantém em aberto a possibilidade de recriar a própria situação social, transformando-a coletivamente.

No cerne da interação entre $I$ e me, como dupla dimensão profundamente imbricada do self, está a capacidade humana de adotar a atitude do outro. Tal capacidade, resultante do aspecto significante do símbolo linguístico, torna-se decisiva para compreender a trama das relações sociais e, particularmente, a própria formação do si-mesmo. Em que consiste, segundo Mead, a capacidade humana de adotar a atitude dos outros? Possuindo vários significados, ela caracteriza, em primeiro lugar, a condição humana de sair de si e, rompendo com a perspectiva solipsista, centrada em si mesma, impulsiona o ser humano para construir seu si-mesmo na 


\section{pro.posıções}

$e$-ISSN 1980-6248

comparação frequente que estabelece com os outros. Este é um mecanismo poderoso de formação do self que começa acontecer já na mais tenra idade e que se aperfeiçoa constantemente ao longo da socialização da criança. O exemplo típico da representação de papéis é a brincadeira com bonecas, por meio da qual, pelo exercício frequente, a criança inventa personagens e desenvolve imaginativamente a capacidade de se colocar no lugar do outro. Assim, ela transforma a boneca na mãe ou professora e, estabelecendo com elas diferentes relações, forma seu próprio self. Contudo, esta formação individual do selfpropiciada pela capacidade imaginativa da criança - e este é o segundo aspecto importante da adoção de papéis - só é possível porque adotar a atitude do outro já é desde o início um processo eminentemente social. Deste modo, embora ocorra na imaginação da criança, a representação de papéis envolve o entorno social, representado simbolicamente pela figura da mãe.

Mead não deixa de pensar situações sociais que deformam o self, impossibilitando-o de assumir sua condição de liberdade criadora. Contudo, como o que nos interessa aqui é a base normativa que sustenta a formação ética do si-mesmo própria ao contexto social democrático, precisamos avançar no último ponto deste tópico, perguntando-nos em que sentido a simpatia torna-se o elo afetivo capaz de impulsionar a formação do si-mesmo na perspectiva da cooperação solidária. Neste contexto, Mead dedica um tópico muito breve em Mind, self and society para tratar da simpatia, concebendo-a como modo ético específico da adoção da atitude do outro ${ }^{13}$. Sendo assim, a simpatia é definida como a emoção que o ser humano sente pela atitude do outro, a quem ele se dispõe a auxiliar, esforçando-se para adotar sua atitude, ao sair em seu socorro. Ou seja, a simpatia é uma forma de afetação ética que o ser humano sente pela condição do outro e, sentindo-se envolvido por ele, busca assumir sua condição. Sofre com o sentimento do outro e busca ajudá-lo.

Neste contexto, Mead atribui dupla dimensão à simpatia, enquanto sentimento de afeto que impulsiona o ser humano a preocupar-se com o outro. A primeira dimensão refere-se ao nível de reciprocidade entre dois agentes: a simpatia depende então que a reação de alguém corresponda à atitude do outro. Deste modo, a postura de um observador distante, completamente alheio ao que acontece com o outro, é justamente o contrário da atitude simpática, a qual exige do agente o tomar parte, tendo que se envolver na situação. A segunda dimensão da simpatia exige que a reação de correspondência recíproca seja acompanhada pela

${ }^{13}$ Referimo-nos aqui ao tópico "A natureza da simpatia” da obra citada de Mead. 


\section{pro.posıções \\ $e$-ISSN 1980-6248}

postura de cooperação. Mas em que consiste tal cooperação? Ela pressupõe primeiramente que quem está sofrendo reaja, mostrando seu sofrimento. Sem a reação que expressa o sofrimento, não há simpatia cooperante. Contudo, também é preciso que o outro perceba o sofrimento manifestado e se torne simpático a ele. Portanto, a cooperação simpática implica a expressão do sofrimento por meio de uma reação e, simultaneamente, a capacidade humana de assumir o sofrimento do outro, tornando-o seu (Mead, 1992, p. 299).

Reconstruímos com isso, em traços bem gerais, alguns aspectos nucleares da formação social do self. No tópico seguinte, mediante a literatura, poderemos imaginar um contexto social no qual o self, embora profundamente deformado, pode vislumbrar alguns lampejos, ainda que muito tênues, da liberdade criadora como constitutiva da condição humana, mas que rapidamente é esmagado pelo peso de estruturas sociais e culturais profundamente opressoras. Neste sentido, o conto "Negrinha", de Monteiro Lobato, nos servirá para compreender melhor, por contraste, o alcance da proposta de formação social do self apoiada na simpatia cooperante como núcleo de formas democráticas de vida. Ou seja, pelo recurso à literatura, podemos observar o quanto formas de vidas dominadas pelo autoritarismo são impedidas de desenvolverem a liberdade criadora.

\section{"Negrinha" e o self deformado}

A extraordinária sensibilidade literária de Monteiro Lobato permite-lhe captar, por meio da narrativa do conto, os traços principais da condição humana profundamente deformada pelas relações sociais de escravidão. A trama entre as diferentes personagens mostra que o pouco de liberdade criadora que existe na ordem social estabelecida restringe-se fundamentalmente à santa Inácia, a qual, por incorporar inconscientemente em sua estrutura psíquica os laços sociais de escravidão, vê limitado o seu próprio horizonte cultural. Vamos reconstruir brevemente a trama estabelecida por "Negrinha", concentrando-nos no perfil e papel de seus personagens principais. 


\section{pro.posıções}

http://dx.doi.org/10.1590/1980-6248-2019-0075

$e$-ISSN 1980-6248

\section{O contexto}

Monteiro Lobato não fornece detalhes específicos do contexto no qual situa o conto intitulado "Negrinha", porém, informa que dona Inácia, também referida como no conto como santa Inácia, "Vinha da escravidão, fora senhora de escravos ... Nunca se afizera ao regime novo - essa indecência de negro igual a branco ...” (Lobato, 2001, p. 79). Tal assertiva nos possibilita visualizar uma realidade na qual as relações entre seres humanos encontra-se diante do desafio nuclear de superar a ideia de que a cor da pele define o status dos interlocutores. Portanto, uma das questões de fundo do conto é a exposição da situação que coloca brancos e negros em trincheiras opostas, numa relação de senhor e escravo naturalizada e, por isso, inteiramente irrefletida. Tal situação é vivenciada nos termos de um jogo em que cada uma das personagens estabelece regras e normas de caráter solipsista, dentro de uma lógica que se movimenta conforme a brisa do humor predominante. Mais grave ainda, tal situação é experienciada sem o concurso da razão singular de cada indivíduo em relação, o que dificulta sobremaneira a percepção daquilo que de fato ocorre consigo e com outrem, obstaculizando a compreensão mais ampla da existência humana. Vejamos agora uma síntese da "realidade" das personagens que destacamos e como o perfil de cada uma delas, entrelaçando-se com o das outras personagens, forma a tessitura social, marcada por um si-mesmo profundamente deformado.

\section{Santa Inácia}

Personagem interessante, santa Inácia representa um dos lados da contenda racial que se desenvolve ao longo do conto de Lobato, que a descreve com evidente sarcasmo e sutil viés satírico. No excerto "Excelente senhora, a patroa. Gorda, rica, dona do mundo, amimada dos padres, com lugar certo na igreja e camarote de luxo reservado no céu” (Lobato, 2001, p. 78), transparece o tácito acordo entre os senhores das terras mundanas com os donos das terras divinas. Afinal, além de ser detentora de propriedade no mundo concreto dos homens, indica Lobato, a boa senhora tem, desde já, reserva especial no paraíso celestial. Pela própria estrutura da relação da senhora com o vigário, na verdade, vislumbra-se, para dona Inácia, uma sequência natural entre a vida na terra e o futuro no Céu. Pois, era tida como virtuosa, religiosa e moral, justamente por conta de suas ações, mui generosamente avaliadas e legitimadas pelo representante das forças divinas, com o qual se vinculava teologicamente. 


\section{pro.posıções \\ $e$-ISSN 1980-6248}

Uma das características de santa Inácia emerge do fato de ser viúva sem filhos, o que resultara, em seu modo de ser, em uma explícita rejeição às crianças filhas de ex-escravos, outrora sob sua tutela legal. Assim, ouvir, mesmo que minimamente, o choro infantil a incomodava imensamente. Via nas crianças nascidas na senzala um modo de superar a frustração que sentia pela perda do poder sobre os escravos que outrora tivera.

Nos tempos em que o conto transcorre, dona Inácia não tem mais o poder de decidir pela vida ou morte dos negros e negras em seu entorno, e não pode, impunemente, puni-los por qualquer desvio. Pior, precisa conviver com suas aspirações de igualdade em relação aos brancos. Reserva, então, às crianças negras, sua propensão de descarregar tensões, o que faz em termos de castigos físicos que pretende sejam exemplares e prova de sua superioridade. Prisioneira de um status quo gerado a partir de uma visão de mundo fomentada pelas forças sociais vigentes - em especial pelo discurso de seu mentor teológico - não percebe o quão distancia-se de sua latente humanidade. Somente por um brevíssimo lapso de tempo percebe, inconscientemente, o outro em sua inteireza humana: isto se dá ao ver a alegria de Negrinha junto às suas duas sobrinhas. Nesta ocorrência, em que as três crianças deixam-se enlevar pela presença da boneca de louça com feições humanas, abandona a postura autoritária e estigmatizadora do outro "inferior" e sua natural propensão a castigá-lo "pedagogicamente". Fazendo brotar uma humanidade antes não existente, influenciada pela vivacidade das sobrinhas e de Negrinha, inclui esta última no espaço social antes desautorizado: torna-se, então, mesmo que por um átimo diminutíssimo de tempo, humana e humanizadora.

\section{As duas sobrinhas}

Dona Inácia recebe, em férias, duas sobrinhas, naturalmente brancas, louras, ricas e “... nascidas e criadas em ninho de plumas" (Lobato, 2001, p. 81). Estas, de forma inconsciente, provocam uma reviravolta na existência de Negrinha, pois, para espanto da menina-escrava, elas irrompem casa adentro aos pulos, risos e gritos - o que, para Negrinha, resultaria em severo castigo, pois para ela, brincar, e ainda mais dentro da casa da senhora, era proibido. Dona Inácia não só não se enfureceu, como inclusive sorriu às meninas, franqueando-lhes a casa e ordenando que as criadas colocassem à disposição os brinquedos que traziam consigo. À curiosidade das duas sobrinhas, que queriam saber quem era Negrinha, dona Inácia informa ser uma caridade sua, uma pobre órfã de Deus que ela, generosamente, cria. 


\section{pro.posições \\ $e$-ISSN 1980-6248}

Em síntese, a vida das sobrinhas consigna uma liberdade gerada pela visão de mundo da autoridade externa, sem qualquer tipo de resistência. "Brincam" na vida com a naturalidade que lhes é inerente em face à tenra idade e gozam dos privilégios que lhes são concedidos, sem qualquer contato mais estreito com a realidade que as circundam. São protegidas por um mundo que consente como absolutamente natural a relação de superioridade-inferioridade entre os seres humanos: dona Inácia e elas próprias sentem-se infinitamente superiores à Negrinha.

\section{Negrinha}

Negrinha, 7 anos de idade, nascida na senzala e filha de escrava, vive sua vida pelos cantos da cozinha da casa onde reina santa Inácia, tendo como cama uma esteira velha e como vestimenta não mais do que trapos sujos. Quase sempre escondida, de preferência invisível e inaudível, algo às vezes complicado, pois açoitam -lhe o corpo a fome e o frio e crispa-lhe a alma o pavor do que a vida poderia lhe trazer em desavisado instante. Diuturnamente assustada, olhos arregalados, magra, órfã desde os quatro anos, uma moradora que "por ali ficou feito gato sem dono, levada a pontapés" (Lobato, 2001, p. 79). Era, constantemente, alvo de zombarias e castigos, sem maiores explicações e mesmo sem sequer algum tipo de justificação - chegando ao cúmulo de ter como contrapartida às suas ações e omissões, ora risos, ora castigos físicos e morais.

Imobilizada em um canto por horas a fio, diariamente tratada como coisa, recebe como alcunha as mais diversas definições, pejorativas e destruidoras da autoestima e da autoconsciência: "Que ideia faria de si essa criança que nunca ouvira uma palavra de carinho?" (Lobato, 2001, p. 79). O episódio da boneca de louça provoca duplo efeito em Negrinha. Primeiro, descobre-se como ser vivo, com alma, humana, o que lhe chega como definitivo e a transforma, sem possibilidade de retroação. Após, sendo-lhe negada manter a descoberta, entristece e murcha em vida, até que de vida a ser vivida nada mais resta, a não ser a venenosa lembrança daquele átimo de tempo em que se percebeu humana. Reminiscência iluminada que lhe atinge mortalmente, pois em pouco tempo sua vida esvai-se em uma névoa que a inunda de delírios com bonecas de louça.

Ao fim desta breve síntese, entendemos que o traço comum das personagens retratadas é a quase total ausência do si-mesmo, com a consequente rendição às imposições sociais, 


\section{pro.posıções}

$e$-ISSN 1980-6248

assumidas sem consciência reflexiva e sem a capacidade de ampliar o olhar na direção de uma visão de mundo que possa incluí-las em um conceito mais largo de humanidade. Entre elas não existe, portanto, o self bifurcado que, constituído pela via de mão dupla, possibilita a liberdade criadora e a própria reciprocidade humana. Sendo assim, está ausente o nível de simpatia cooperante que Mead considera indispensável à formação ética do si, decisiva à existência do ambiente social democrático.

\section{Lampejos de autogoverno: Negrinha à luz da formação do si- mesmo}

Monteiro Lobato expressa, neste conto, o drama humano representado por seus personagens, os quais, mesmo marcados pelo contexto social escravizante, dominado por relações autoritárias, buscam sendas de liberdade criadora. Há, deste modo, uma ambiguidade que cruza a formação humana típica dos mais diferentes contextos sociais, que se acentua naqueles contextos em que praticamente inexiste a liberdade criadora. Se em contextos autoritários o ser humano vê sua liberdade impedida, mesmo assim vai ao seu encontro, tão logo ocorra a flexibilização mínima do autoritarismo aparentemente irrestrito. Neste sentido, é paradigmático o drama vivido por Negrinha, que, sem conhecer sequer uma pequena fagulha de liberdade criadora, anima-se tão logo percebe sua existência, mesmo que por um instante fugidio, tão fugaz como um belo e eletrizante fogo de artifício.

Deste modo, no conto de Lobato, a despeito do que se possa conceber como relações vivenciadas com acentuado nível de inconsciência da interdependência entre seres humanos, há um momento em que tal questão é superada. Referimo-nos à chegada das duas sobrinhas de dona Inácia, que, inadvertidamente, colocam em xeque o status quo. Ao irromperem casa adentro "como dois anjos do céu - alegres, pulando e rindo com a vivacidade de cachorrinhos novos" (Lobato, 2001, p. 81), alteram o quadro interativo padrão - marcado pela indiferença em relação ao humano - e provocam mudanças momentâneas na percepção dos indivíduos.

Negrinha, às voltas com o doce enlevo provocado pela boneca de louça com feições humanas trazida pelas duas sobrinhas; estas, em êxtase diante do espanto de Negrinha com a boneca entre os braços; dona Inácia, apreciando a cena, detendo o passo, abrandando a alma e abrindo o coração. Tal configuração interativa expressa a capacidade de alterar as reações, pois 


\section{pro.posıções}

$e$-ISSN 1980-6248

dona Inácia, fria e feroz defensora da "ordem” em sua casa, e Negrinha, fraca e indefesa diante da realidade em que vive, reagem de maneira diferente à situação. Isso mostra que, mesmo diante do contexto social profundamente marcado por relações escravistas e escravizantes, ainda foi possível emergir um lampejo de liberdade criadora, o qual é rapidamente sufocado pelo peso de relações sociais e culturais profundamente desiguais e, por conseguinte, pela força esmagadora do hábito embrutecedor da tradição. Em um contexto marcado por relações sociais autoritárias não há como a liberdade criadora encontrar seu espaço de fermentação. É solo estéril que impede a germinação da nova planta.

Contudo, por mais árido que seja o terreno, sempre há uma rachadura para que a planta brote e siga seu curso. Para dona Inácia, mostrou-se tão vibrante o quadro de alegria de suas sobrinhas, somado à radiante felicidade de Negrinha, que "o seu duro coração afinal bambeou. E pela primeira vez na vida foi mulher. Apiedou-se" (Lobato, 2001, p. 82). Ou seja, a compreensão de dona Inácia em relação à ocorrência ímpar em seu cotidiano vai além do habitual. Neste, sua postura seria de agressividade diante da petulância de Negrinha, coisa inferior, de misturar-se aos seus, superiores por natureza divina e solidificada pelas relações sociais escravistas. A essa atitude, bem o sabiam todos, adviriam sonoras reprimendas e duros castigos. Para espanto geral, dona Inácia, diante do quadro, anuncia "Vão todas brincar no jardim, e vá você também, mas veja lá hein?” (Lobato, 2001, p. 82). Aos ouvidos da pequena escrava, há suavidade e doçura nestas palavras, ouvidas neste tom pela vez primeira em sua sofrida existência. Tanta era sua alegria por ser tratada como igual pela primeira vez "que nem deu bola" para a reprimenda contida na expressão “mas veja lá, hein”.

Pensamos que, à dona Inácia, este momento representa a libertação de seu hábito internalizado sem a devida reflexão, no qual se assenhorava rudemente das "almas inferiores", de seus outrora escravos. O efeito deste átimo de liberdade faz-se presente no olhar enternecido e brando - humano, portanto - às suas duas sobrinhas e a Negrinha, repercutindo nesta o tratamento que a inclui na espécie humana. Para Negrinha, a experiência em curso repercute profundamente, pois ao deter o olhar na figura de dona Inácia - olhar desde sempre carregado de temor pelo que adviria - nota a mudança. Em vez da ferocidade habitual de sua "bemfeitora", recebe dela doces palavras e um olhar que demonstra a presença de humanidade, algo assaz compreendido por Negrinha, que, fato raríssimo, sorri. O que resulta na constatação de que "Se alguma vez a gratidão sorriu na vida, foi naquela surrada carinha" (Lobato, 2001, p. 83). Negrinha, maltratada pela vida, considerada como coisa entre coisas, tratada pelos mais baixos 


\section{pro.posıções}

http://dx.doi.org/10.1590/1980-6248-2019-0075

$e$-ISSN 1980-6248

e degradantes adjetivos, sorri com gratidão. Muito provavelmente por dar-se conta de que possuía, em si mesma, alma, ou seja, o esboço de um self, sentindo-se "elevada à altura de ente humano" (Lobato, 2001, p. 83). Para a infante escrava, este momento representa a soltura dos grilhões sociais que a colocavam sob a tutela de outrem e de si mesma na internalização irrefletida de um status quo imposto, ao qual sucumbia sem esboçar reação alguma. O efeito da liberação dos grilhões reflete na autopercepção de Negrinha de que é, sim, bumana.

O advento narrado mostra que o material subjacente à relação conturbada das personagens - prisioneira cada qual a seu jeito de uma dada conformação social - é o bumano, ainda que em sua forma primitiva e dependente de desenvolvimento consciente. Humano que encontra no espaço social a possibilidade de emergir em função de que, neste, como bem anuncia Mead, a perspectiva de relações linguísticas expressadas por meio de símbolos significantes potencializa a formação do si-mesmo, a qual, quando acompanhada pela simpatia cooperante, orienta a interação social na perspectiva solidária. Fato é que a base normativa inerente à proposta de formação do si-mesmo, visando contextos sociais democráticos, voltase claramente contra atitude de obediência e servidão. Deste modo, o conto de Monteiro Lobato, uma vez analisado à luz desta perspectiva meadiana, como procuramos fazer, força-nos a ver lampejos, mesmo que tênues e breves, de liberdade criadora na ação dos personagens, ao mesmo tempo que nos leva a criticar tudo o que aparece como sentimento de superioridade irrestrita que aniquila a possibilidade do autogoverno individual.

\section{Educação como formação humana}

Mesmo que haja alguns lampejos de liberdade criadora no conto de Monteiro Lobato, o que predomina é a ausência da educação na perspectiva da formação humana. Liberadas dos grilões da escravidão, as personagens sorriem por instantes fugazes, mas tornam-se rapidamente carrancudas e calejadas pela força do hábito. Voltam a consentir novamente, de maneira inquestionável, a relação, profundamente deformadora à condição humana, de superioridadeinferioridade. Gostaríamos de analisar, neste último tópico de nosso ensaio, mais de perto este aspecto ambíguo que constitui a ideia de educação como formação humana: se a formação ligase umbilicalmente à autoformação, ela também contém em si, como um aspecto que a constitui ontologicamente, a possibilidade do fracasso. Ou seja, é parte constitutiva da base normativa da 


\section{pro.posıções \\ $e$-ISSN 1980-6248}

ideia de formação humana que ela pode não acontecer, ou acontecer somente pela metade, como algo destrutivo. Exatamente nesta perspectiva destrutiva, a formação humana torna-se deformação, ou seja, Bildung als Unbildung.

\section{Formação como deformação do si-mesmo}

Como marca característica da realidade existencial das personagens do conto de Monteiro Lobato há, a nosso ver, a ausência de uma educação que intente colocar o outro em perspectiva de inclusão, possibilitando que sua singularidade apareça. Pelo contrário, na realidade delas grassa a desconsideração inconsciente para com o diferente e, até mesmo, poderse-ia afirmar que não há o olhar na direção de um sujeito, e sim a simples percepção do outro como objeto.

Dona Inácia, prisioneira de sua propensão desmesurada à superioridade, dominada por sua soberba inflamada, no doce enlevo proveniente do discurso do vigário que a coloca como virtuose, vive imersa em ilusões acerca de sua dimensão existencial e moral. Isto é, associando-se a um horizonte interno egocêntrico, impõe-se um manancial de considerações externas que a coloca em grilhões inexpugnáveis: com a proteção divina, coloca-se acima de tudo e de todos, tratando Negrinha como mero objeto. As duas sobrinhas, por sua vez, vivem em uma redoma de vidro que as coloca em área de segurança e conforto. Possuem liberdades jamais sonhadas por Negrinha, tendo disponíveis para si recursos lúdicos fartos, e, de quebra, transitam pela vida tendo, por um lado, a proteção dos adultos e, por outro, a submissão destes. Desta forma, vivem uma liberdade fictícia, marcada pela inconsciência da interdependência traduzida na invisibilidade do outro, ao mesmo tempo que se mantêm subservientes à própria alma infantil. Negrinha, a seu tempo, tem todas as suas prerrogativas humanas negadas e soterradas sob o manto da "normalidade" recém-instituída que, sob certos aspectos, a coloca não mais como escrava e, sob outros, a mantém justamente como tal. Recebe o indulto, a alforria, legalmente estabelecida, mas não pode usufruí-la, pois não encontra em seu grupo social ambiente formativo adequado para que sua liberdade criadora se desenvolva. Reduzida à condição de objeto, Negrinha está distante de ter consciência de si. 


\section{pro.posições}

$e$-ISSN 1980-6248

Das três realidades existenciais, resulta ao fim e ao cabo, uma relação simbiótica, retratada por Georg W. F. Hegel (1998) na metáfora do senhor e do escravo. Na referida simbiose, santa Inácia exerce seu poder graças a tríplice e contínua corrente: sua origem familiar, o referendo eclesiástico e a submissão dos fisicamente recém-libertos que, na prática, conservam os grilhões da mente intactos. As duas sobrinhas, por conta da pouca idade e do provável excesso de proteção, distanciam-se da realidade que as cercam, livres e enjauladas a um só tempo, pois não lhes é facultado o desafio de lidar diretamente com o mundo real. Negrinha, por conta de seu passado escravo (ainda presente), sequer se percebe como humana e, justamente ao perceber-se viva e vibrante, com "alma", aniquila-se diante da tensão entre não poder mais ser coisa nem se afirmar como gente. Impotente, é coisa entre coisas, não podendo expor vontades sem castigos: tem, como tarefa quase existencial, o dom de servir de desafogo às frustrações de dona Inácia e à cegueira alienante enraizada em seus semelhantes. Contudo, com inspiração na referida metáfora de Hegel, é possível perceber que dona Inácia só consegue assegurar sua posição de "superioridade" por causa da existência de Negrinha, e, sem a obediência irrestrita desta, santa Inácia jamais seria dona Inácia.

Não há na constituição individual dos personagens ora em evidência a formação humana na perspectiva da simpatia cooperante, porque as relações entre elas são concebidas desde o início como relações naturalizadas de superioridade-inferioridade. Bem ao contrário, em vez da formação humana baseada na simpatia cooperante, predomina a "deformação" dos personagens, caracterizando uma notável ausência de visão do ser humano como humano; percebe-se, como material subjacente ao enredo, a desconsideração de si mesmo como sujeito ativo e cooperante. A ausência da ideia de educação como formação humana baseada na simpatia cooperante é o motor deformativo que impulsiona a manutenção do status quo imposto de maneira despercebida aos envolvidos, mantendo-os prisioneiros de outrem e de si mesmos, sem possibilidade de exercerem sua liberdade criadora. Como resultado, há a impossibilidade do pleno desenvolvimento do si-mesmo e, como efeito imediato, a cristalização da propensão humana à superioridade, claramente manifestada na postura onipotente e autoritária de dona

${ }^{14}$ Entendemos aqui por deformação (Unbildung) um estágio inferior e ainda mais degradante do que semiformação (Halbbildung). Neste sentido, se a semiformação já se distancia significativamente de formação (Bildung) como autoformação (Selbstbildung), a deformação significa o empobrecimento ainda maior da experiência humana formativa. Sobre a comparação crítica entre estes conceitos e o modo como eles se entrelaçam no âmbito da educação contemporânea, ver Konrad Paul Liessmann (2012, pp. 212-222). 


\section{pro.posıções \\ $e$-ISSN 1980-6248}

Inácia: aniquila Negrinha sem dó ou piedade, ou seja, segundo o vocabulário de Mead, sem qualquer sentimento de simpatia cooperante.

\section{Formação humana como autoformação}

O conto de Monteiro Lobato ilustra uma situação social na qual a formação humana aparece claramente como deformação, uma vez que nela predomina a posição de infinita superioridade de uma personagem sobre as demais. Além disso, quem é colocado na posição de inferioridade, no caso, a personagem Negrinha, aceita isso com naturalidade, assumindo espontaneamente a condição de obediência irrestrita. Contudo, formação humana não é obviamente só obediência e servidão irrestritas, pois pode significar, como vimos, a busca incessante pelo autogoverno baseada na simpatia cooperante. Na sequência, gostaríamos de precisar melhor esta ideia, rastreando sua origem na moderna tradição da Bildung, da qual Mead também é notadamente tributário. Nesta tradição, destacam-se Jean-Jacques Rousseau e Immanuel Kant. O ponto em comum entre estes dois autores, embora vivam em contextos culturais bem distintos, é a compreensão de formação humana como um campo de tensão (Kraftfeld) que, marcado por processos ambíguos, pode assumir sentido tanto positivo como negativo. ${ }^{15}$

Rousseau insere a ideia de formação humana na teoria da ambiguidade do amor próprio, a qual ele deriva da tese antropológica mais ampla de que a condição humana é constituída pelo amor a si mesmo (l'amour de sol), sentimento geral que constitui de uma maneira ou outra a fonte de todas as paixões humanas (Rousseau, 1999). Deste sentimento maior originam-se dois outros: amor de si mesmo (amour de soi-même) e amor próprio (amour propre). Enquanto o primeiro caracteriza a condição humana em seu estado natural, marcado pela piedade e autoconservação, o amour propre é um sentimento eminentemente moral, que nasce com a sociabilidade humana, na mesma proporção que se torna sua principal mola propulsora. Como sentimento moral, o amour propre torna-se força destrutiva quando movido por paixões odientas e irascíveis, mas converte-se em força construtiva se movido pelos ideais de bondade e justiça. Em síntese, segundo Rousseau, a formação do si-mesmo depende da educabilidade virtuosa do aspecto destrutivo de seu amor próprio, que brota de sua sociabilidade. Do domínio das paixões

${ }^{15}$ Para uma interpretação da formação humana como campo de força, ver Claudio Almir Dalbosco (2019, pp. 35-64). 


\section{pro.posıções}

$e$-ISSN 1980-6248

destrutivas (envenenadas) depende o próprio autogoverno que o ser humano pode fazer de sua vida, preparando-se eticamente para o convívio social solidário com seus semelhantes.

Como herdeiro alemão direto do pensamento de Rousseau, Kant também parte da pressuposição antropológica da sociabilidade insociável (ungesellige Geselligkeit) do ser humano, concebendo-a como motor do desenvolvimento das capacidades humanas. Isso caracteriza a própria ambiguidade da condição humana, uma vez que o ser humano pode unir-se aos seus semelhantes movido pela cooperação solidária ou por sentimentos puramente egoístas, visando assegurar somente seus interesses individuais. Fato é que, para Kant, este antagonismo caracteriza a dimensão social da condição humana e a maioridade pedagógica inicia precisamente pelo enfrentamento de tal antagonismo. Sendo assim, Kant, do mesmo modo que Rousseau, atribui dimensão moral à formação humana, exigindo do pensar por conta própria o trabalho que o sujeito precisa fazer consigo mesmo para enfrentar o aspecto destrutivo de sua própria insociabilidade. Ora, o aspecto relevante, do ponto de vista pedagógico, é que este domínio virtuoso é resultado de um longo e inesgotável processo formativo que o sujeito precisa fazer consigo mesmo na companhia de outros sujeitos inseridos no amplo ambiente.

Portanto, Rousseau e Kant acentuam, cada um a seu modo, a ideia de formação como autoformação. Com isso traçam as linhas gerais da própria ideia de formação humana desenvolvida no século XIX, decisiva à formação do self pensada por Mead. Gostaríamos de percorrer agora, brevemente, apenas um fio desta enorme e densa trama. Se, como acabamos de ver, formação é autoformação, como é tecido o fio que precisamos puxar para compreendêla? A ideia de autoformação traz consigo uma dupla dimensão, entrelaçada entre si: a primeira, que abarca nitidamente o aspecto individual, depende do interesse e da vontade do próprio educando: por mais competente e comprometido que o educador seja, ele não consegue ir adiante com seu trabalho se não há interesse do educando. Neste sentido, autoformação significa postura ativa do educando, dispondo-se para a formação. A segunda dimensão da autoformação caracteriza seu aspecto propriamente social, no sentido de que a própria postura ativa do educando, com seu respectivo interesse, precisa ser desencadeada por forças externas, pela ação do educador, pela força do grupo social mais próximo e pelo ambiente mais amplo. Vê-se, então, que a autoformação de modo algum é um processo simples, que ocorre espontaneamente, uma vez que se constitui pelo campo de força no qual atuam várias personagens simultaneamente, implicando tanto o interesse e a vontade individual, como as forças e os conflitos sociais que o influenciam. 


\section{pro.posıções \\ e-ISSN 1980-6248}

Como herdeiro direto desta longa tradição, Georg Herbert Mead pensa a formação do si-mesmo como autoformação, compreendendo-a também como constituída pelo campo de força. Deste modo, a figura metafórica do self bifurcado em $I$ e me representa precisamente este campo de força entre o individual e o social e, ao mesmo tempo, uma maneira criativa de tentar solucionar os impasses que daí resultam, recorrendo à noção-chave de interação humana mediada simbolicamente. Decisivo para a bifurcação do selfé a distinção entre gesto e símbolo: enquanto o gesto é um mecanismo mais instintivo empregado para provocar estímulos nos outros e no ambiente, sem a internalização de significados, o símbolo caracteriza-se pela capacidade humana de internalizar gestos vocais e externalizá-los posteriormente, com novos significados. No âmbito desta dinâmica, enquanto o $I$ representa a dimensão propriamente individual que internaliza as pressões do meio, reelaborando-as criativamente, o me é uma espécie de "eu social”, que faz chegar até o I as próprias pressões sociais. Sem a interferência da sociedade, o I não teria o material suficiente para sua criação, ao mesmo tempo que sem a internalização criativa do $I$, o me se perderia no turbilhão social, deixando-se arrastar pela correnteza da propensão humana à superioridade escravizante.

Em síntese, com Mead e a moderna tradição da Bildung podemos afirmar que a ideia de educação como formação humana na perspectiva da autoformação impulsiona o desenvolvimento de estruturas sociais abertas e democráticas na mesma medida que depende delas para ocorrer. É decisivo, nesse contexto, dar continuidade ao esforço intelectual de revisitar criticamente a tradição cultural, filosófico-pedagógica, para atualizar referências normativas que se contraponham a qualquer forma de estrutura social fechada, que acentua a propensão humana à superioridade autoritária e aniquila o exercício da liberdade humana criadora. É tal confronto que mantém viva a chama da liberdade criadora, força capaz de se insurgir contra o conservadorismo autoritário e obscurantista.

\section{Considerações conclusivas}

Nossa reflexão desdobrou-se em quatro momentos, cujos resultados principais gostaríamos de destacar agora. No primeiro procuramos reconstruir aspectos da teoria interacionista da educação de Mead, enfatizando seu aspecto social-intersubjetivo. Tal aspecto repousa na teoria simbólica da ação humana, dando origem à bifurcação do self em $I$ e me, que, 


\section{pro.posıções}

$e$-ISSN 1980-6248

aos próprios olhos de Mead, quando orientada pela simpatia cooperante, assegura a capacidade intersubjetiva da condição humana. Problematizamos inicialmente o significado da ação mediada simbolicamente, distinguindo, neste contexto, ação gestual e ação simbólica, e mostrando o quanto o sentido significante da ação simbólica torna-se decisivo à teoria intersubjetiva da ação humana. Na sequência, ainda no primeiro momento de nosso ensaio, nos ocupamos com a estrutura bifurcada do self, assinalando sua diferença na mesma medida que destacamos sua profunda e mútua dependência. Tal estrutura mostra a capacidade autorreflexiva da condição humana que, ao ser movida pela simpatia cooperante, dá origem à sociabilidade solidária.

No segundo momento recorremos ao conto "Negrinha", de Monteiro Lobato, para mostrar, à contrapelo, como a ação humana pode descambar facilmente para a obediência irrestrita e o quanto isso marca negativamente as formas de vida, impedindo-as de darem origem à liberdade criadora. Deste modo, a relação estabelecida entre dona Inácia e Negrinha é exemplar paradigmaticamente para ilustrar a formação humana como deformação, representando, deste modo, a própria ausência de autoformação. No terceiro tópico, confrontamos o conto de Monteiro Lobato com aspectos da teoria de Mead para evidenciar a tensão constitutiva da formação como autoformação, a qual repousa na disposição ativa do sujeito: mesmo possuindo a propensão à liberdade criadora e podendo fazer uso dela na perspectiva da simpatia cooperante, o ser humano, sobretudo quando está mediante estruturas sociais autoritárias, tende à obediência irrestrita. Por fim, reconstruímos, em linhas gerais, no último tópico do ensaio, um traço da formação como autoformação, herdado por Mead da Modernidade, o qual o influencia decisivamente para elaborar sua teoria da formação do self. Contando com os avanços do pensamento de sua época, Mead pôde assinalar, de maneira mais clara do que seus antecessores, a dimensão social-intersubjetiva da formação humana como autoformação, isto porque soube fazer uso de aspectos linguísticos da sociabilidade humana, formulando com base nisso sua teoria interacionista da educação.

Mead mantém, com isso, o aspecto ativo que caracteriza a ideia moderna de formação como autoformação. Mas, como a concebe no âmbito da teoria da interação humana mediada simbolicamente, torna visível a dimensão social e intersubjetiva que apenas estava latente na ideia rousseauniana e kantiana de autoformação. Isso torna ainda mais clara a tarefa ética da educação, uma vez que a formação do self entrelaça-se às estruturas institucionais abertas, preservando simultaneamente o espaço para a liberdade criadora. O aspecto intersubjetivo 


\section{pro.posições}

$e$-ISSN 1980-6248

inerente à formação do si-mesmo baseada na simpatia cooperante torna-se indispensável para atender, numa perspectiva normativa de reconhecimento do outro, as exigências pluralistas que caracterizam as formas contemporâneas de vida. Deste modo, a teoria desenvolvida por Mead pretende dar conta de problemas que se põem no âmbito público movido pela capacidade humana de se autogovernar, oriunda da intersubjetividade constituída linguisticamente.

Encontramo-nos em um âmbito social e cultural muito distante daquele marcado pela obediência irrestrita que define a relação de Negrinha com dona Inácia e toma conta quase por inteiro do espaço social exprimido. O espaço social de obediência irrestrita é exatamente o oposto do âmbito sociocultural movido pela interação mediada simbolicamente, no qual a formação do si-mesmo visando sua autonomia tem melhores chances de acontecer. De outra parte, o modo como Mead pensa a formação humana como autoformação serve de alerta para evitar que, mesmo em contextos sociais democráticos, a própria formação descambe para deformação, impedindo que as novas gerações façam uso criativo e eticamente relevante de sua liberdade. Embora estejamos distantes do contexto social marcado pela servidão irrestrita, não faltam, no momento presente, propósitos políticos de querer reavivá-la a qualquer preço. Por isso, revisitar criticamente a tradição cultural passada, buscando atualizar a ideia de formação humana como autoformação, continua sendo uma tarefa intelectual e política indispensável às teorias educacionais críticas.

\section{Referências}

Dalbosco, C. A. (2010). Pragmatismo, teoria crítica e educação. Campinas: Autores Associados.

Dalbosco, C. A. (2011). Kant \& a educação. Belo Horizonte: Autêntica.

Dalbosco, C. A. (2014). Die sprachliche Konstitution des Selbst (Self) und die pädagogische Handlung. Pädagogische Rundschau, 68, 251-262.

Dalbosco, C. A. (2016). Condição humana e educação do amor-próprio em Jean-Jacques Rousseau. São Paulo: Loyola.

Dalbosco, C. A. (2019). Metamorfoses do conceito de formação: da teleologia fixa ao campo de força. In C. A. Dalbosco, E. H. Mühl, \& H.-G. Flickinger (Eds.), Formação bumana (Bildung): despedida ou renascimento? (pp. 35-64). São Paulo: Cortez Editora. 


\section{pro.posições \\ $e$-ISSN 1980-6248}

Freire, P. (2009). Pedagogia da autonomia: saberes necessários à prática educativa. São Paulo: Paz e Terra.

Hegel, G. W. F. (1988). Phänomenologie des Geistes. Hamburg: Meiner.

Habermas, J. (1992). Nachmetaphysisches Denken: Philosophische Aufsätre. Frankfurt am Main: Suhrkamp.

Honneth, A. (1994). Kampf um Anerkennung: Zur moralischen Grammatik sozialer Konflikte. Frankfurt am Main: Suhrkamp.

Joas, H. (2000). Praktische Intersubjektivität: die Entwicklung des Werkes von G. H. Mead. Frankfurt am Main: Suhrkamp.

Kant, I. (1998). Beantwortung der Frage: was ist Aufklärung? In Werke in sechs Bänden (Herausgegeben von Wilhelm Weischedel, Vol. 4, pp. 53-61). Darmstadt: Wissenschaftliche Buchgesellschaft.

Liessmann, P. K. (2012). Theorie der Unbildung. In H. Hastedt (Ed.), Was ist Bildung?: Eine Textanthologie (pp. 212-222). Stuttgart: Reclam.

Lobato, M. (2001). Negrinha. In I Moriconi (Ed.), Os cem melhores contos brasileiros do século (pp. 78-84). Rio de Janeiro: Objetiva.

Mead, G. H. (1992). Mind, self and society: from the standpoint of a social behaviorist. Chicago: University of Chicago Press.

Mead, G. H. (2010). Espiritu, persona y sociedad: desde el punto de vista del conductismo social. Madrid, Paidós.

Rousseau, J.-J. (1999). Emile (Oeuvres complètes, Vol. 4). Paris: Gallimard.

Teixeira, A. (2000). Pequena introdução à filosofia da educação: a escola progressiva ou a transformação da escola. Rio de Janeiro: DP\&A.

Tugendhat, E. (1997). Selbstbewusstsein und Selbstbestimmung: Sprachanalytische Interpretationen. Frankfurt am Main: Suhrkamp.

Submetido à avaliação em 12 de junho de 2019; aceito para publicação em 10 de outubro de 2019. 